\title{
Drought and crop production in Chengde City: Based on Logistic and Prais-Winsten regression analysis
}

\author{
Keller Jiang ${ }^{1, a, *}$ \\ ${ }^{1}$ School of Geography and Environment, Jiangxi Normal University, Nanchang Jiangxi, China;
}

\begin{abstract}
Drought has a great impact on agricultural production and threatens food security. Chengde city is located in the border of North China and Inner Mongolia Plateau, where drought often occurs. In this study, logistic regression and multiple regression were used to analyze the relationship between drought and grain yield. It is found that drought is an important reason for agricultural production reduction.
\end{abstract}

\section{Introduction}

Drought is one of the most destructive natural disasters, causing huge economic and ecological losses [1-2]. Due to the close relationship between drought and food security [3], scholars often pay attention to the problem of drought [4-5]. Since 2004, China's grain output has reached a record high for 15 consecutive years and stabilized at more than 1.3 trillion Jin for five consecutive years. But earlier, China's agricultural production was more affected by meteorological disasters, and crop production was unstable. Especially in northern China, precipitation is an important factor restricting agricultural development. This study established the relationship between drought and crop production, which has guiding significance for agricultural production.

\section{Research area, data and methods}

\subsection{Survey of Research Areas}

Chengde is located in the northeastern part of Hebei Province $\left(40^{\circ} 12^{\prime}-42^{\circ} 37^{\prime} \mathrm{N}, 115^{\circ} 54^{\prime}-119^{\circ} 15^{\prime} \mathrm{E}\right)$, which is the transition zone connecting North China and Northeast China. The district of the city is located in the Yanbei Mountains and the Inner Mongolia Plateau in the north. It belongs to the transition zone from warm temperate zone to sub-frigid zone. It has a semi-humid and semi-arid continental monsoon climate. The average annual precipitation in the urban area is $519.8 \mathrm{~mm}$. The city has large interannual precipitation changes and rainy years The precipitation is $835.9 \mathrm{~mm}$, and the annual precipitation is $326.7 \mathrm{~mm}$ with low rainfall. The ecological environment is relatively fragile. The precipitation in Chengde City is mainly concentrated in July and August. The precipitation in the two months exceeds half of the annual precipitation. There is little precipitation in spring and spring drought is prone to occur.

Chengde's agriculture is dominated by food crops grown in dry land, including corn, sorghum, and millet. Drought is one of the main factors affecting agricultural production in Chengde.

Table 1: Monthly average precipitation in Chengde City

\begin{tabular}{|l|l|l|l|l|l|l|l|l|l|l|l|l|l|}
\hline Month & 1 & 2 & 3 & 4 & 5 & 6 & 7 & 8 & 9 & 10 & 11 & 12 & Total \\
\hline Precipitation & 2.0 & 4.3 & 7.4 & 21.9 & 43.7 & 83.8 & 145.8 & 133.6 & 49.0 & 20.8 & 5.2 & 2.2 & 519.8 \\
\hline
\end{tabular}

(Data source: Chengde Meteorological Bureau)

\subsection{Data}

This study collected the cumulative intensity and maximum intensity of the extreme drought in Chengde from 1961 to 1990 , and the population data, planting area and output value data from 1960 to 1990. Stata 15 was used to analyze the impact of drought on the unit output value of the planting industry in Chengde.

Table 2: Variable list

\begin{tabular}{|c|c|}
\hline $\mathrm{Y}_{1}$ & whether the output is reduced \\
\hline $\mathrm{Y}_{2}$ & the output value of planting industry \\
\hline $\mathrm{X}_{1}$ & the planting area \\
\hline
\end{tabular}




\begin{tabular}{|c|c|}
\hline $\mathrm{X}_{2}$ & the number of population at the end of the year \\
\hline $\mathrm{X}_{3}$ & the maximum value of annual extreme drought intensity \\
\hline $\mathrm{X}_{4}$ & the average value of extreme drought cumulative intensity \\
\hline $\mathrm{X}_{5}$ & the frequency of drought. \\
\hline
\end{tabular}

\subsection{Methods}

The correlation coefficient was used to judge the impact, and the relationship between drought and crop production was established by logistic regression and Prais-Winsten regression.

\section{Process}

\subsection{Normal distribution test}

Through normal distribution test, we can judge whether the correlation should be determined by parametric method or nonparametric method.

Table 3: Normal distribution test

\begin{tabular}{|l|l|l|l|l|l|}
\hline Variable & Obs & Pr(Skewness) & $\operatorname{Pr}($ Kurtosis) & adj chi2(2) & Prob>chi2 \\
\hline $\mathrm{Y}_{1}$ & 31 & 0.4372 & 0.7566 & 0.73 & 0.6929 \\
\hline $\mathrm{X}_{1}$ & 31 & 0.2010 & 0.3583 & 2.70 & 0.2591 \\
\hline $\mathrm{X}_{2}$ & 30 & 0.6116 & 0.0238 & 5.21 & 0.0737 \\
\hline $\mathrm{X}_{3}$ & 30 & 0.0204 & 0.9474 & 5.22 & 0.0735 \\
\hline $\mathrm{X}_{4}$ & 30 & 0.1185 & 0.9637 & 2.66 & 0.2640 \\
\hline $\mathrm{X}_{5}$ & 30 & 0.0013 & 0.0074 & 13.45 & 0.0012 \\
\hline
\end{tabular}

From the test results, $\mathrm{X}_{2}, \mathrm{X}_{3}$ close to the significance level of $0.05, \mathrm{X}_{5}$ is less than the significance level of 0.05 , the test correlation should be non parametric method.

\subsection{Pearson rank sum test}

Since the variables do not conform to the normal distribution, the Spearman rank sum test was used to analyze the relationship between variables.

From the results of correlation coefficient, the effect of continuous drought is more significant than that of short-term extreme drought.

Table 4: Pearson rank sum test

\begin{tabular}{|c|c|c|c|c|c|}
\hline Variable & $\mathrm{X}_{1}$ & $\mathrm{X}_{2}$ & $\mathrm{X}_{3}$ & $\mathrm{X}_{4}$ & $\mathrm{X}_{5}$ \\
\hline spearman & -0.5519 & 0.7264 & -0.1153 & -0.2153 & 0.1662 \\
& $* *$ & $* * *$ & & & \\
\hline Prob $>|\mathrm{t}|$ & 0.0016 & 0.0000 & 0.5441 & 0.0531 & 0.3802 \\
\hline
\end{tabular}

\section{Result}

From the perspective of time series, the output value of the planting industry was greatly affected by drought before the reform and opening up, and the change in the agricultural output value after the reform and opening up was significantly less affected by the drought. 


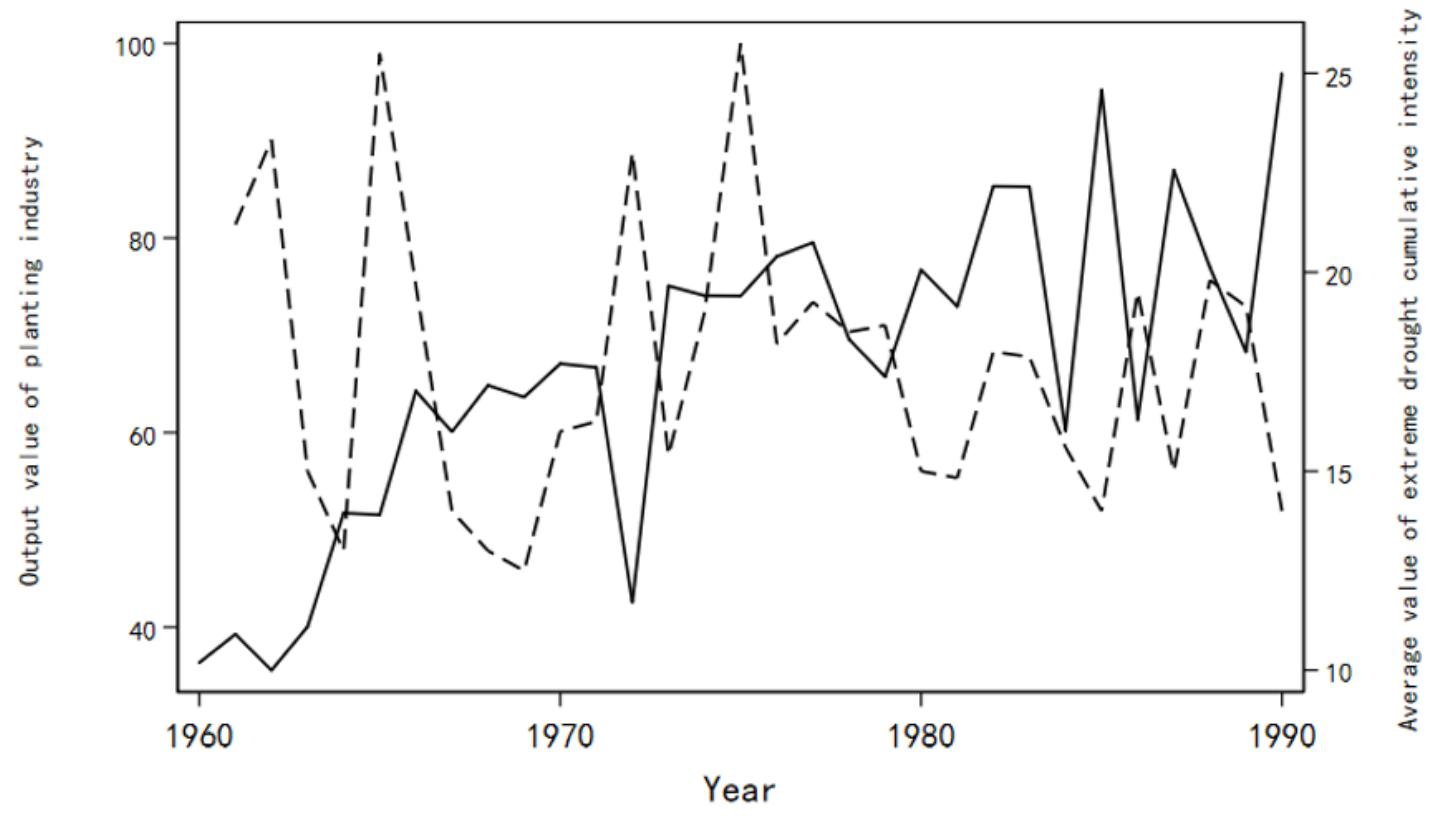

- Output value of planting industry
--- Average value of extreme drought cumulative intensity

Figure 1: average cumulative drought degree and planting output value

\subsection{Logistic regression}

$\mathrm{Y}_{1}$ is the binary variable and the $\mathrm{X}_{4}$ is independent variable, the logistic univariate regression analysis was carried out. Finally, the model is obtained.

Logit $\mathrm{Y}_{1}=1.3014 \mathrm{X}_{4}+0.0115$ (1)
From the regression results, the average value of extreme drought accumulation intensity has a significant correlation with the yield reduction of planting industry in Chengde city.

Table 5: Logistic regression results

\begin{tabular}{|l|l|l|l|l|ll|}
\hline Variable & Odds Ratio & Std. Err. & $\mathrm{z}$ & $\mathrm{P}>\mathrm{z}$ & {$[$ [95\% Conf.Interval] } \\
\hline $\mathrm{X}_{4}$ & 1.301353 & .1728902 & 1.98 & 0.047 & {$[1.00302$} & $1.688422]$ \\
\hline Cons & .0115227 & .0267298 & -1.92 & 0.054 & {$[.0001222$} & $1.08675]$ \\
\hline
\end{tabular}

\subsection{Prais-Winsten regression}

Using the Prais-Winsten regression, $\mathrm{X}_{1}, \mathrm{X}_{2}, \mathrm{X}_{4}$ should be

Table 6: The results of Prais-Winsten regression

\begin{tabular}{|c|c|c|c|c|cc|}
\hline Variable & Coef & Std. Err. & $\mathrm{t}$ & $\begin{array}{c}\mathrm{P}>\mathrm{t} \\
(95 \%)\end{array}$ & [95\% Conf. Interval] \\
\hline $\mathrm{X}_{1}$ & 563.7104 & 241.602 & 2.33 & 0.028 & 67.09029 & 1060.331 \\
\hline $\mathrm{X}_{2}$ & .1793125 & .0330018 & 5.43 & 0.000 & .1114763 & .2471488 \\
\hline $\mathrm{X}_{4}$ & -1031.919 & 475.4389 & -2.17 & 0.039 & -2009.198 & -54.64029 \\
\hline cons & -339744.6 & 149285.7 & -2.28 & 0.031 & -646605.7 & -32883.48 \\
\hline
\end{tabular}

Table 7: Analysis of model variance

\begin{tabular}{|l|l|l|l|}
\hline Source & SS & df & MS \\
\hline Model & $7.7263 \mathrm{e}+09$ & 3 & $2.5754 \mathrm{e}+09$ \\
\hline Residual & $2.2639 \mathrm{e}+09$ & 26 & 87071752.8 \\
\hline Total & $9.9902 \mathrm{e}+09$ & 29 & 344490046 \\
\hline
\end{tabular}


The model significance level $\mathrm{P}<0.0001 ; \mathrm{R} 2$ is 0.7734; The adjusted R2 is 0.7472 ; D-W original value 2.35206; D-W converted value 1.971624. The model has high significance level, good fitting degree and no significant autocorrelation. According to the regression results, the output value of planting industry decreased by 1031.92 yuan per unit of annual extreme drought accumulation intensity in Chengde city.

\section{Conclusion}

From 1960 to 1990, the planting production in Chengde city was not stable. Especially before the reform and opening up, the planting industry in Chengde city was greatly affected by drought. But the impact of drought on crop production is not decisive. After the reform and opening up, with the development of planting technology, the impact of drought becomes smaller.

\section{References}

1. NOAA National Centers for Environmental Information (NCEI). (2019) U.S. Billion-Dollar Weather and Climate Disasters. Accessed March 25, 2019

2. A. AghaKouchak, A. Farahmand, F.S. Melton et al., (2015) Drought characterization from a multivariate perspective: A review. J. Hydrol., 527, pp. 668-678

3. M.C. Anderson, C.A. Zolin, P.C. Sentelhas et al. (2016) The Evaporative Stress Index as an indicator of agricultural drought in Brazil: an assessment based on crop yield impacts. Remote Sens. Environ., 174, pp. 82-99

4. C. Yu, et al. (2014) Dynamic assessment of the impact of drought on agricultural yield and scaledependent return periods over large geographic regions. Environ. Model Softw., 62, pp. 454-464.

5. S. Madadgar, A. AghaKouchak, A. Farahmand, S.J. Davis. (2017) Probabilistic estimates of drought impacts on agricultural production. Geophys. Res. Lett., 44 (15), pp. 7799-7807 